\title{
Solid-State Distributed Temperature Control for International Space Station
}

\author{
Jon B. Holladay \\ Shawn E. Reagan \\ NASAMMarshall Space Flight Center \\ Greg Day \\ The Boeing Company
}

Copyright (C) 2004 SAE Intemational

\begin{abstract}
A newly developed solid-state temperature controller will offer greater flexibility in the thermal control of aerospace vehicle structures. A status of the hardware development along with its implementation on the MultiPurpose Logistics Module will be provided. Numerous advantages of the device will also be discussed with regards to current and future flight vehicle implementations.

\section{Introduction}

The Multi-Purpose Logistics Module (MPLM) is the primary container for transportation of logistics to and from the International Space Station. Designed to support a shirt sleeve environment, the 20 foot long by 15 foot diameter aluminum canister can transport and maintain 20,000 pounds of payload in a benign environment (60 to 80 deg $F$ with a maximum dew-point of 60 deg F) similar to that seen in a controlled warehouse or scientific laboratory. Maintenance of the temperature within the MPLM is obtained by passive design and active monitoring and control of the internal ambient conditions. Shell heaters located on the MPLM structural skin provide heat input to the structure with temperature control accomplished via bi-metallic thermostats.
\end{abstract}

The initial MPLM design utilized 3200 Series Elmwood Thermostats with a single pole, single throw switch activated by a snap action bi-metallic disk. This design nominally provided a temperature control band from 84 to $98 \mathrm{deg} F$ (81 to 101 deg $F$ maximum range). Unfortunately the large control band poses several problems ranging from inefficient utilization of power resources to activation of pressure relief valves.

A new solid-state distributed controller (thermostat) has been designed and implemented which will allow improved operational capability and more efficient utilization of Orbiter cryogenic fuel resources. Integration of the new hardware has also been performed with very minimal impact via utilization of the existing power cable. The wires are cut and the new thermostat, as depicted in Figure 1, is simply spliced into the circuit.

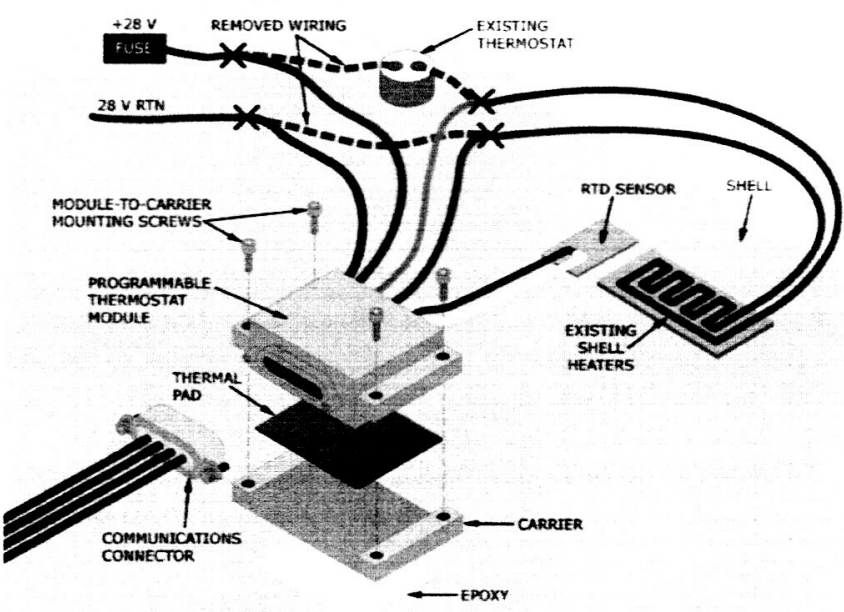

MPLM PROGRAMMABLE THERMOSTAT HARDWARE

Figure 1. Programmable Thermostat Hardware

\section{Current Hardware Concept}

The objective of the programmable thermostat development and installation program is to replace the current Passive Thermal Control Subsystem (PTCS) 28 Volt DC thermostats on the MPLM structural shell with state of the art programmable devices. This upgrade will improve the efficiency of the MPLM on-orbit shell heater operations by providing better shell temperature control through the use of programmable set points with closed loop feedback control capability and tighter control bands. This feature results in more efficient MPLM power consumption from the Shuttle. On-orbit MPLM shell heater operations are necessary in order to provide thermal conditioning to prevent condensation from forming inside the MPLM and to prevent the NPRA (negative pressure relief assembly) from opening upon de-orbit.

The programmable thermostat is an electronic assembly used in conjunction with a Resistance Temperature Device (RTD) and heaters to provide temperature control for the exterior surface and interior environment of the MPLM. This device will consist of an electronic thermostat module, mechanical interface assembly, 
- RTD, communication cable, and a data recorder. Each MPLM will have 20 thermostat/RTD assemblies and 1 data recorder installed. The electronic thermostat will be capable of cycling +28 Volt DC power (maximum 5 amperes) to the heater element(s) based on the control temperature set point, the control span, and the RTD. The RTD will allow for closed loop control capability of each thermostat by providing continuous temperature monitoring capability. The communication cable (RS485 serial interface) will connect each programmable thermostat to a single data recorder. The data recorder will record the shell temperature from the RTDs, the on/off cycles of thermostats, and other health and status information. This data can be downloaded after the mission is complete for post-flight analysis. The data recorder will also provide the means by which each thermostat's set point and control span may be programmed during ground processing using a Ground Support Equipment (GSE) computer.

The installed programmable thermostat and RTD sensor is shown in Figure 1. The mounting carrier consists of an aluminum bracket bonded to the MPLM external pressure shell. The programmable thermostat will be secured to the mounting bracket via mounting screws (bolts, etc). This installation design allows for easy replacement of failed units.

The RTD will be mounted no more than 36 (and no closer than 6 inches) from the thermostat electronics module and near the existing bi-metallic thermostats. Mounting distance of the thermostats was optimized by analysis utilizing Systems Improved Numerical Differencing Analyzer (SINDA). The maximum distance is driven by controllability of the heater zones while the minimum distance is chosen to avoid thermal contamination of the sensor by the controller.

\section{Development}

Development of the electronic thermostats has a long history that was initiated during the MPLM preliminary design phase. Although NASA management would accept the risk (outlined previously) to proceed with bimetallic thermostats, sound project and risk management insured that the issue was not filed away. After acceptance of the three MPLM flight elements it was determined that implementation of the solid state thermostats would greatly enhance the hardware performance. Two sets of thermostats and data recorders are now on-dock at KSC awaiting integration.

\section{IIlla History}

During the MPLM In-Process Review held in 1997, a Review Item Discrepancy was written against the MPLM design with regard to set band / hysteresis risk with the bi-metallic thermostat performance. However, after an exhaustive market survey it was discovered that a commercially available design alternative did not exist either in the aerospace or general sector and management agreed to accept the risk with MPLM development. The risk was maintained and tracked through development and acceptance of the three
MPLM flight units with an understanding that if required, two solution options existed. The first option was to place constraints on the system and manually operate the shell heaters via activation and termination of power to the heater circuit. The second solution was implementation of a solid-state thermostat that was not currently available on the commercial market. Although a solid-state design was not available at that time, previous technology development work performed by NASA in the 1980s had actually demonstrated manufacture and performance of a breadboard unit. However, technology transfer regulations did not allow sharing of this information.

Early in the year 2000, after acceptance of the first MPLM Flight Module, integration activities began. This included analysis of the vehicle performance for the initial flight(s) and development/refinement of operational flight rules. Initial analysis (performed by Alenia Aerospazio) of the MPLM mission with no operational constraints included the internal volume pressure profile shown in Figure 2. As one would expect the pressure relief valves are in a continuous chatter trying to minimize the pressure increase from the heaters, which are controlled via the bi-metallic thermostats. After approximately four days of burping, the valves begin to reach equilibrium with the heat input. Equilibrium does not occur until after a considerable release of air (a consumable commodity that would require make-up from the Space Station). Risk to mission success would also be greatly increased due to the possibility of a relief valve failure to reseat and the consequent inability to berth the MPLM to the Space Station.

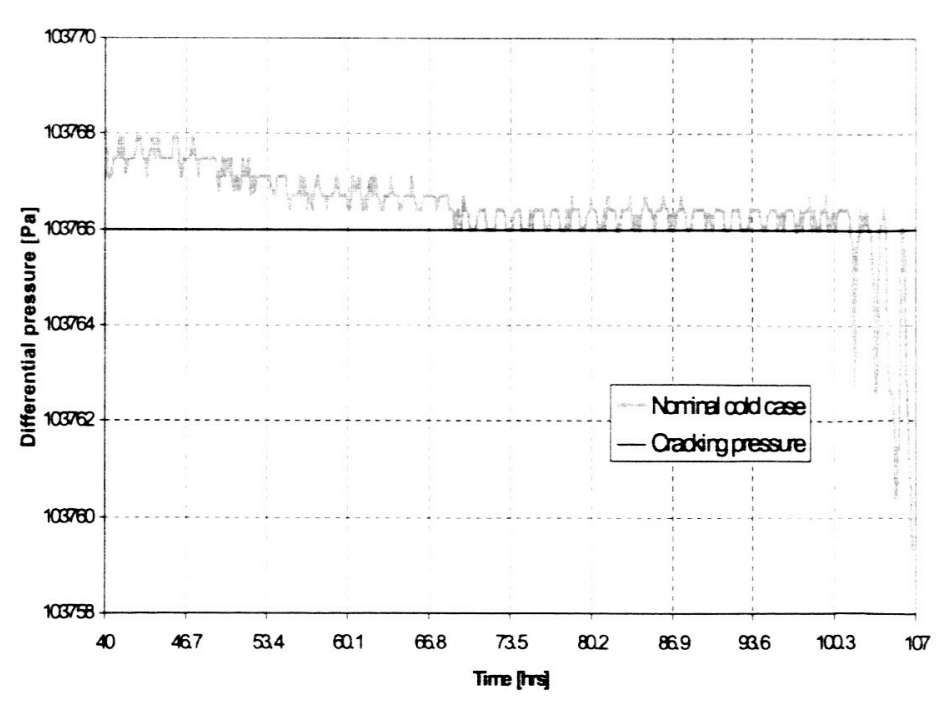

Figure 2. Initial Analysis of PPRV Operations

It was anticipated that the existing mechanical thermostats could be utilized for passive MPLM flights and possibly for future active flights if tight enough constraints could be placed on ground and flight closeout activities. In order to quantify this solution, analyses had to be performed to evaluate no modification and also understand if a more desirable alternative existed. 
- In April of 2000 the results of that assessment were provided to the ISSPO for information. The primary issues were threefold and included PPRV cracking, unnecessary usage of Orbiter cryogenic resources (for shell heater power generation) and an ancillary concern from payloads over the possible maximum temperature exposure (115 deg Fahrenheit). Results of the assessment indicated that the "baseline" design did not pose a hazard impact to Orbiter operations during any mission phase. However, the risk of repeated valve cracking did expose a risk of a valve not reseating and subsequent venting of the MPLM environment which also means inability to ingress and loss of mission.

Seven options as listed below were evaluated for possible implementation. Options 3,4 and 5 were the only ones that met the requirement of eliminating PPRV cracking. Option 3 was later eliminated due to uncertainty in analysis accuracy and the less efficient use of Orbiter resources. Option 3 also required a closed loop purge of the MPLM cabin for dew-point reduction which resulted in additional flight hardware cost for IMV caps and it had an expanded low end temperature range of $40 \mathrm{deg} F$.

1. Baseline w/Pre-Launch Purge

2. Baseline w/Heaters Activated Pre-Launch

3. Cycle Heaters by Analysis

4. Cycle Heaters by Analysis \& Monitor Real-Time

5. Change-out Mechanical Thermostats for Solid State Design

6. Change Thermostats to Similar Mechanical Design \& Add PVGF

7. Change Thermostats, Add PVGF, Resize HCU and Heaters

With an understanding that viable solutions exists further analyses was undertaken utilizing the "quasi" test verified MPLM thermal and geometric mathematical models running on a SINDA thermal solver to validate the system capability using manual control. These results are provided in Figures 3 and 4 . Grey and Blue bars at the top of the plot indicate crew pre-sleep, sleep and post-sleep intervals to confirm timing of Orbiter switch throws to control power to the MPLM shell heaters.

Option 3 however did require expansion of the low-side dew-point temperature to less than $\mathbf{5 0}$ deg $F$. For passive missions without a late access requirement, this was not an issue. The module could be purged while still in the processing facility with no impact to schedule.

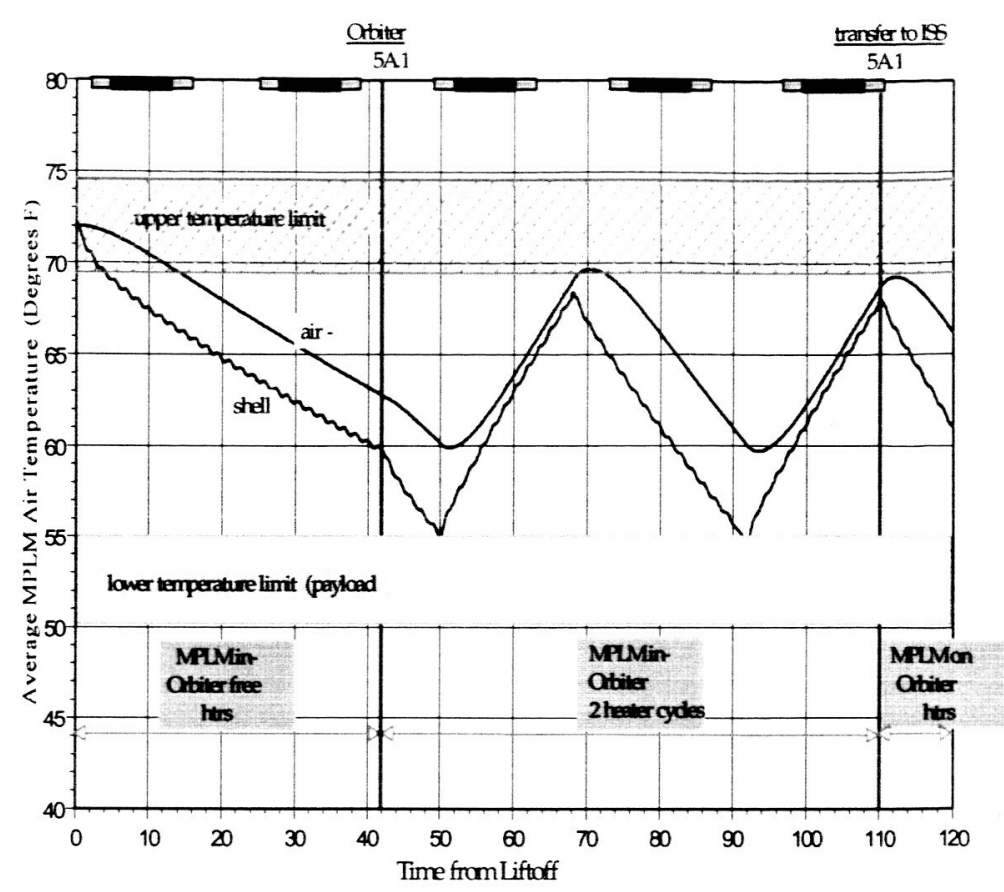

Figure 3. Option 3, Cold Case XVV

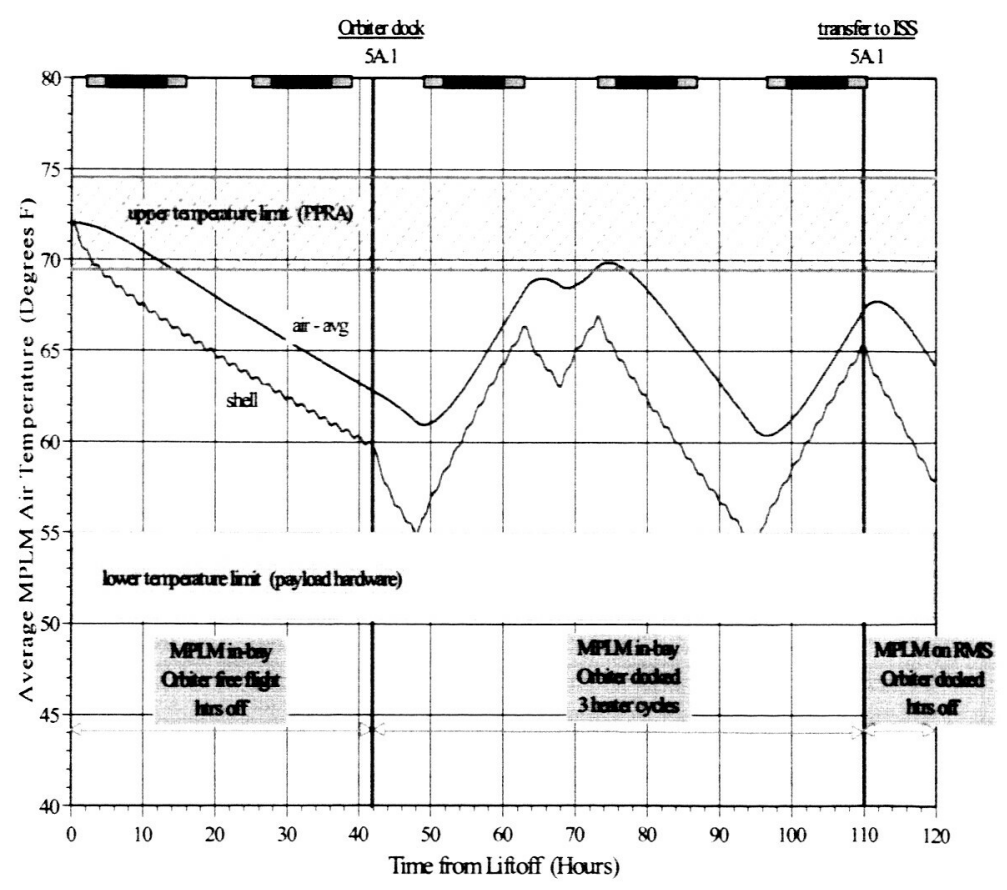

Figure 4. Option 3, Cold Case XPOP

For active flights with refrigerated cargo this lack of impact was not clear. In response to the concern Kennedy Space Center (KSC) performed an evaluation of the time required to do ground servicing on the launch pad for dew-point reduction. Results of the process analysis provided in Figure 5 indicated that time was not 
available in the flow to meet late access science installation requirements and purge the cabin within the allotted Orbiter launch processing schedule. Further evaluation of Option 4 was required.

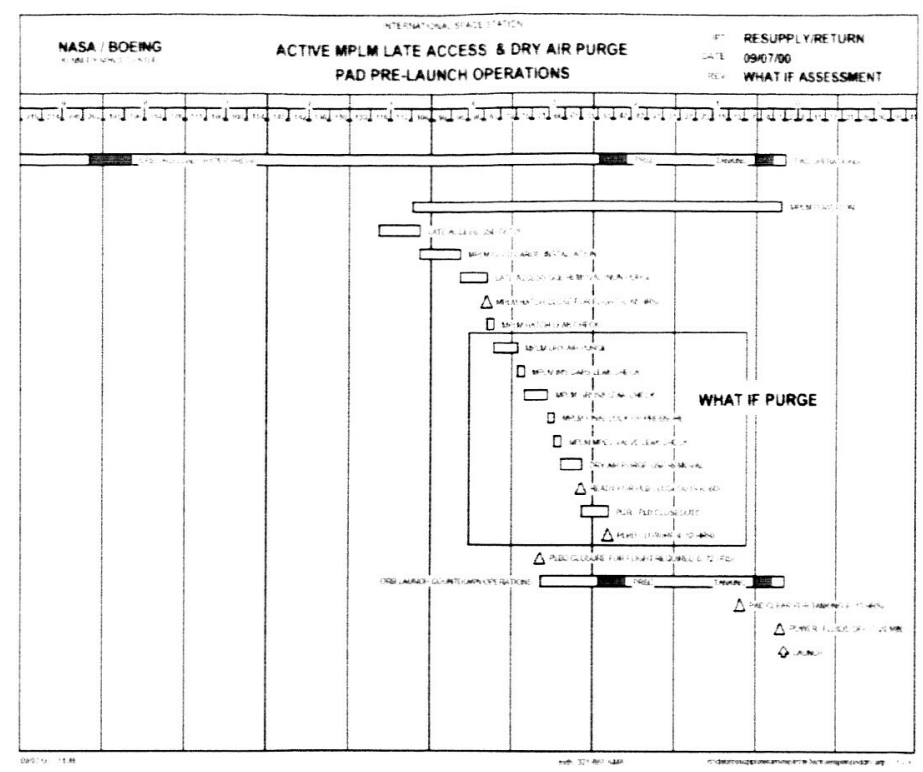

Figure 5. Active MPLM: Late Access \& Dry Air Purge

Analyses similar to those for Option 3 were then performed with the simulated thermostat control capability. The results, shown in Figure 6., indicated that sufficient capability with the proposed design did exist to eliminate the dry air purge, minimize risk for PPRV cracking, and also provide a more benign range of temperature excursion.

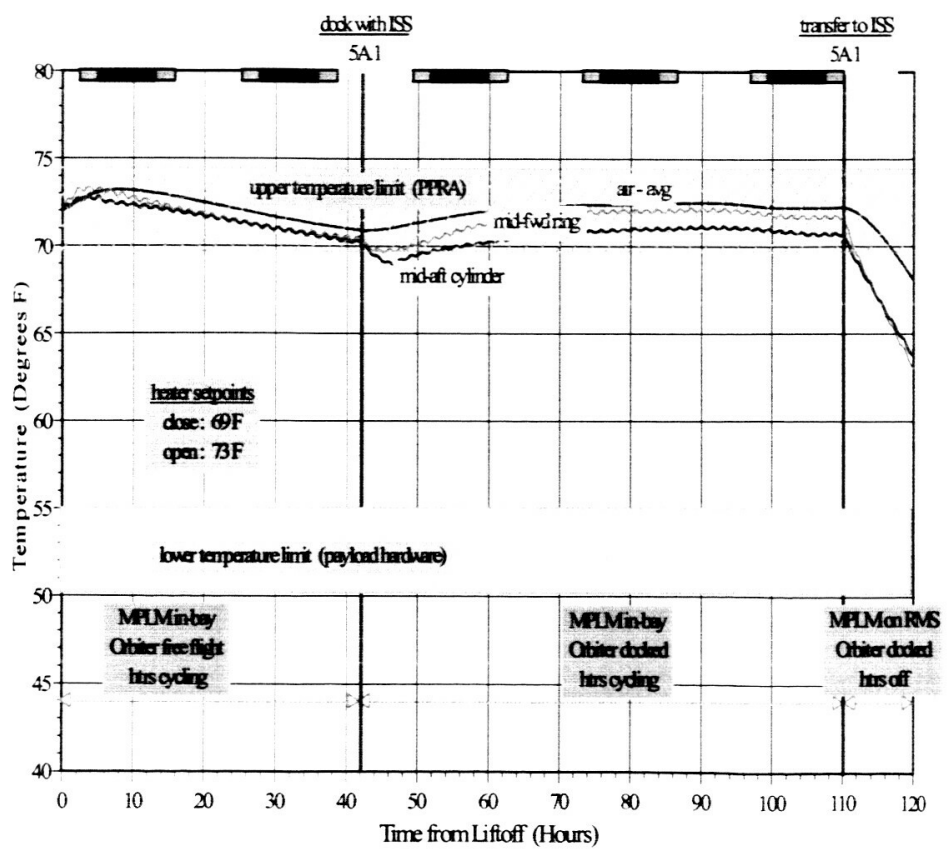

Figure 6. Worst Case Cold Analysis

Option 4 has been utilized on the first five MPLM flights and includes a pre-launch dry air purge, $10 \mathrm{deg} F$ relaxation of low temp requirement ( 60 to $50 \operatorname{deg} F$ ), and real-time monitoring and manual control of the heater power circuits. This approach has been very successful and is documented in 2003-ICES-2516. Detailed information on the first five MPLM flight performances can also be found in 2003-ICES-2517. The alternative, Option 5, to install a solid state controller with tighter setpoint bands was approved by Change Request in October 2000, with all three MPLM flight units delivered to KSC the decision to replace the MPLM thermostats was approved by the ISS Vehicle Control Board and is now in work.

\section{IIllb Status}

As of March 2004, the first flight set of programmable thermostats and a data recorder have been built, tested, and shipped to Kennedy Space Center (KSC) in Florida for installation on the MPLM Flight Module 1 (FM1). Installation on FM1 is scheduled for mid-Spring 2004. This shipment was preceded by a comprehensive qualification and acceptance test campaign that included electromagnetic effects, vibration, and thermal testing. The vibration levels and thermal cycles during qualification testing were set such that the hardware is qualified for 25 flights - the life of each MPLM. Figure 7 shows the qualification and acceptance vibration levels. Figure 8 outlines the qualification and acceptance thermal cycling ranges. All testing during the formal qualification and acceptance campaigns were successful with no failures noted.

\begin{tabular}{|c|c|c|}
\hline Frequency $(\mathrm{Hz})$ & $\begin{array}{c}\text { Qualification } \\
\text { Level }\end{array}$ & $\begin{array}{c}\text { Acceptance } \\
\text { Level }\end{array}$ \\
\hline 20 & $0.04 \mathrm{~g}^{2} / \mathrm{Hz}$ & $0.01 \mathrm{~g}^{2} / \mathrm{Hz}$ \\
\hline 20 to 65 & $\begin{array}{c}+7.6 \\
\mathrm{~dB} / \text { Octave }\end{array}$ & $\begin{array}{c}+7.6 \\
\text { dB/Octave }\end{array}$ \\
\hline 65 to 180 & $0.8 \mathrm{~g}^{2} / \mathrm{Hz}$ & $0.2 \mathrm{~g}^{2} / \mathrm{Hz}$ \\
\hline 180 to 360 & $-7.0 \mathrm{~dB} /$ Octave & $\begin{array}{c}-7.0 \\
\mathrm{~dB} / \text { Octave }\end{array}$ \\
\hline 360 & $0.16 \mathrm{~g}^{2} / \mathrm{Hz}$ & $0.04 \mathrm{~g}^{2} / \mathrm{Hz}$ \\
\hline 360 to 1400 & $-2.6 \mathrm{~dB} /$ Octave & $\begin{array}{c}-2.6 \\
\mathrm{~dB} / \text { Octave }\end{array}$ \\
\hline 1400 & $0.05 \mathrm{~g}^{2} / \mathrm{Hz}$ & $0.0125 \mathrm{~g}^{2} / \mathrm{Hz}$ \\
\hline 1400 to 2000 & $\begin{array}{c}-4.9 \\
\mathrm{~dB} / \text { Octave }\end{array}$ & $\begin{array}{c}-4.9 \\
\mathrm{~dB} / \text { Octave }\end{array}$ \\
\hline 2000 & $0.028 \mathrm{~g}^{2} / \mathrm{Hz}$ & $0.007 \mathrm{~g}^{2} / \mathrm{Hz}$ \\
\hline Composite & $16.8 \mathrm{~g}_{\mathrm{ms}}$ & $8.4 \mathrm{~g}_{\mathrm{rms}}$ \\
\hline
\end{tabular}

Figure 7. Qualification and Acceptance Vibration Levels.

\begin{tabular}{|l|c|c|c|}
\hline & $\begin{array}{c}\text { Low } \\
\text { Temperature }\end{array}$ & $\begin{array}{c}\text { High } \\
\text { Temperature }\end{array}$ & $\begin{array}{c}\text { \# of } \\
\text { Cycles }\end{array}$ \\
\hline Qualification & $-24^{\circ} \mathrm{F}$ & $+156^{\circ} \mathrm{F}$ & 24 \\
\hline Acceptance & $-4^{\circ} \mathrm{F}$ & $+136^{\circ} \mathrm{F}$ & 8 \\
\hline
\end{tabular}

Figure 8. Thermal Cycle Ranges. 
The second flight set, to be installed on MPLM FM2, has undergone acceptance vibration and thermal testing at Marshall Space Flight Center (MSFC) and is being readied for shipment to KSC. The printed circuit boards for the third (and final) flight set as well as all the spare modules have been populated and tested at the board level. They must still be placed in the housings and the housings must be filled with the potting compound. The acceptance testing of this set should be complete by mid-Summer 2004 and the remaining units will be shipped to KSC to await installation.

\section{Illc Capability}

The GSE software designed to operate with the thermostats can be used to set the set point and control span of each thermostat individually, or a "broadcast" command may be used to set each thermostat to the same set point and control span. During the first flight of the programmable thermostats, all thermostats will be set to the same set point and span. Once the postmission data has been analyzed to determine the hot and cold spots of the MPLM, the next mission will have thermostats set uniquely in order to provide a more even temperature distribution.

The set points of the thermostats can range from $5^{\circ} \mathrm{C}$ to $45^{\circ} \mathrm{C}$ with a control span ranging from $1^{\circ} \mathrm{C}$ to $10^{\circ} \mathrm{C}$. The control span determines the range around the set point that the thermostat will cycle. For example, assume a thermostat has a set point of $72^{\circ} \mathrm{F}$ with a control span of $2^{\circ} \mathrm{F}$. The thermostat will turn on the heaters when the RTD reads $71^{\circ} \mathrm{F}$ and will turn the heaters off when the RTD reads $73^{\circ} \mathrm{F}$.

The data recorder is sized in order to capture a full mission's worth of data without being dumped during the mission. In order to ensure this, the temperatures and other data are recorded at a rate of once per minute. Once the mission is complete and the MPLM is undergoing post-mission processing, the GSE computer will be hooked to the recorder for download of data.

\section{Future Benefits}

Numerous benefits (i.e., streamlined operations, automated checkout, lower power consumption, etc) will be achieved with integration of the new solid-state thermostats. Leveraging of the distributed control system is also a first step in evaluation of enhancements to future vehicles. Addition of a wireless communication and control system could easily be added to the hardware subsystem as a Development Test Objective (DTO) to perform flight test certification of a hybrid network. Derivatives of the current box design can also be easily integrated into the exiting system to evaluate "smart" components which would adjust and take over failed components improving system reliability. Although these options have not been evaluated or approved they are being maintained much as the initial development risk with the intent that a flight test bed is available as the need might arise.

\section{llc Conclusion}

The solid state controllers and data recorder have been under budget and within schedule to assist the MPLM in meeting performance requirements for the first active mission flow, UF-5, scheduled for flight in 2007 . It is expected that evaluation of flight performance will provide additional information valuable to improving analytical capabilities. Furthermore, tailoring of the thermostat set-point per heater zone will also allow additional performance from the MPLM to be achieved, thus reducing Orbiter cryogenic "power" consumption and thus improving mission resource efficiency. These improvements along with future capabilities for technology evaluation are expected to far exceed the initial implementation cost.

\section{Acronyms}

ASI - Agencia Spaziale Italiano

HCU - Heater Control Unit

IMV - Intra-Module Ventilation

KSC - Kennedy Space Center

ISSPO - International Space Station Program Office

MSFC - Marshall Space Flight Center

MPLM - Multi-Purpose Logistics Modules

NASA - National Aeronautics and Space Administration

PVGF - Power Video Grapple Fixture

\section{References}

2003-01-2516, The International Space Station's MultiPurpose Logistics Module: Thermal Performance of the First Five Flights,

2003-01-2517, An Integrated Approach to Thermal Management of International Space Station Logistics Flights: Improving the Efficiency,

MSFC-SPEC-3274, Programmable Thermostat End Item Specification

MSFC-SPEC-3322, Data Recorder End Item Specification

MLM-TN-Al-0174, Heaters/Thermostats Definition and Installation, 11 Apr 1997

MLM-RP-AI-0169, Heaters and Thermostats (TCS S/S) Stress Analysis, 09 Sep 1997

MLM-RP-AI-0019, MPLM Baseline Configuration Report, 31 March 1998

SINDAFluint General Purpose Thermal/Fluid Netwrok Analyzer, Version 4.4, July 2001 